\title{
A rapid method for evaluating the variables affecting traffic flow in a touristic road, Iran
}

\author{
Neda Kardani-Yazd ${ }^{1}$, Nadia Kardani-Yazd ${ }^{2}$ and Mohammad Reza Mansouri Daneshvar ${ }^{3^{*}}$ (1)
}

\begin{abstract}
Background: This study aimed to evaluate variables that influence traffic flow and its contribution to touristic transportation in a touristic road, Iran. The traffic flow data were extracted from the hour-by-hour data in 2018 from a local traffic control center in addition to three daily indices, including climatic comfort indicator, temperature inversion indicator, and temporal indicator of local calendar events, which were obtained from databases and equations. The data time series were arranged into diurnal, weekly, and monthly scales to apply in correlation tests.

Results: Results revealed that a rate of $18-25 \%$ of total transportation (about 3,500,000-5,000,000 vehicles from total $19,828,619$ vehicles) was assumed as a touristic portion of the traffic flow in the study area. The relationships between independent variables and traffic flow data exposed the effective and considerable role of the local climate on the traffic flow at above $98 \%$ of confidence level, without a strong association between calendar effect and traffic flow. Statistical results in all temporal cycles revealed the significant positive and negative effects of the local climatic comfort index and temperature inversion index on the traffic flow, respectively.

Conclusions: The finding of this study described that the traffic flow and touristic transportation in the study area are more affected by the local climatic comfort and temperature inversion indices, but are less affected by the local calendar holidays and occasional vacations. Hence, the decision-makers in the study area sternly need a fundamental climatic calendar for management, tourism transportation, and traffic flow instead of the current local calendar.
\end{abstract}

Keywords: Traffic flow, Climatic comfort, Temperature inversion, Calendar events, Tourism transportation

\section{Introduction}

Many urban and suburb roads today experience increasing traffic flow that threatens the environment and transport efficiency. Knowledge about traffic flows is essential at many levels of traffic management and transport policy to tackle the problems (Jenelius and Koutsopoulos 2013). Concerning the traffic flow issues, most of the urban areas exploit transportation management procedures (Madhuwanthi et al. 2016), e.g., remote detection of traffic volume and vulnerability. The high intensity of traffic, inadequate infrastructure, and the irrational distribution of the development are the main reasons for increasing traffic flow

\footnotetext{
*Correspondence: mrm_daneshvar2012@yahoo.com

${ }^{3}$ Department of Geography and Natural Hazards, Research Institute of Shakhes Pajouh, Isfahan, Iran

Full list of author information is available at the end of the article
}

(Abdel-Aal et al. 2018). Besides, urban planning management has a significant impact on levels of traffic flow, defined as the number of vehicles per unit time (Arasan and Koshy 2005). It also defined as the number of cars crossing or passing in a specific section of a road (Cools et al. 2010).

Investigation of the transportation systems during urban and regional planning has a significant role in promoting traffic flow and making sound and sustainable decisions (Bertolini et al. 2005; Bikdeli et al. 2017). The procedures to investigate transportation systems have extended based on statistical and spatial models using traffic data and transport demand (Kitamura 2009; White 2009), road networks (Yigitcanlar et al. 2007), e.g., transport accessibility (Wixey et al. 2005), transportation process (Liu and Zhu 2004), and transportation remoteness index (ABS 2001).

A large body of researches has examined the connections between the climate and urban transport systems 
concerning the effects of climatic elements, such as temperature, humidity, precipitation, and wind, on the travels and following traffic flow. In this regard, climate change has the potential to impact significantly on the efficiency, safety, and cost of the transportation systems (Jaroszweski et al. 2014). Koetse and Rietveld (2009) have pointed out the approach to analyze the influence of climatic and non-climatic variables to consider temporal variations in transport and traffic flow. They noted that the climatic effects on the transportation systems could be explained weekly, monthly, and seasonally. Furthermore, the nonclimatic temporal effect, such as local calendar holidays and occasional vacations, could be taken into account as a triggering factor in the transportation system.

Kim (2018) has revealed different effects of local calendar events on the transport demand of a public bike system in South Korea. Nevertheless, there is a lack of study to investigate day-to-day causal relationships between traffic flow and independent time series such as the local calendar events and local climatic indices. Temporal cycles (weekly and monthly) of the aforementioned timeseries can indicate the demand for transportation and traffic flow, especially in a touristic zone such as the study area in this research.

Torqabeh region is located in an ecological zone with several touristic destinations, which absorb annually nearby $\sim 20$ million vehicles. This region is the main touristic destination of western Mashhad city without any comprehensive traffic program to manage the touristic flows and to plan the transpiration variables. According to the lack of traffic evaluation in the study area, this study aims to investigate the essential variables that influence on traffic flow of the study area as a way to detect and manage the touristic share of transportation. For this purpose, the instantaneous relationships between climatic/non-climatic variables and traffic flow are evaluated. We anticipate that this research would provide a rapid method for evaluating the objectives concerning traffic flow control, tourism transportation, and urban management.

\section{Data and methods \\ Study area}

This study focuses on a touristic road, which is elongated from the western suburb of the Mashhad city, with a population of 3,000,000 inhabitants, to Torqabeh city and its touristic hinterland, with a population of 100,000 inhabitants. Touristic region of the Torqabeh with a surface area of $500 \mathrm{~km}^{2}$ is laid between latitudes $36^{\circ} 10^{\prime}-36^{\circ} 30^{\prime} \mathrm{N}$ and longitudes $59^{\circ} 10^{\prime}-59^{\circ} 30^{\prime} \mathrm{E}$, in northeastern Iran, and includes some foremost villages and destinations, named as Jagarq, Nogondar, Kang, Dehbar, Mayan, and Azgad, locating in the northern hills and valleys of Binaloud Mountain (Fig. 1). In a natural view, the elevation of the study area varies from 1000 to $2000 \mathrm{~m}$ above sea level (ASL), and it has a semi-arid region with a mean annual temperature of $15{ }^{\circ} \mathrm{C}$ and an annual rainfall of $300 \mathrm{~mm}$ (Hijmans et al. 2005).

In a general view, the study area has the environmental potential to development (Bikdeli 2019) due to the expanding of the physical, functional, and transportation growth of Mashhad city in this touristic hinterland. This growth is the current pattern of sprawl expansion in the study area (Rabbani et al. 2017), which follows to build up the touristic activities and resorts.

\section{Data preparation \\ Dependent variable}

The traffic flow data were extracted from the hour-byhour data using the loop detector of the traffic control center and transport organization of Torqabeh city for the whole 365 days in 2018 via http://www.tott.ir. The location of the mentioned detector is in the first lane of the road departing from the Mashhad to Torqabeh (Fig. 1). The road is characterized dominantly by three lanes in each direction (two lanes in some places), used both for commuting and leisure traffic from urban settlements to touristic resorts (Fig. 2). The limit threshed of speed in this road is equal to $80 \mathrm{~km}$ per hour. In-situ camera tracking of the loop detector generates several statistics regarding the counting of the vehicles, types of vehicles, and the average speed of traffic flow. For a general argument, this study focused only on vehicle counting, derived from the traffic detector, as the dependent variable. Hourly distribution of raw traffic flow in 2018 was produced in Table 1 after the total hour-by-hour detector of total vehicles. The distribution of detecting vehicle frequencies in each hour by total frequency revealed that the hourly peak of traffic flow in the study area belongs to the 19 UTC with 1,457,964 total vehicle detecting (Fig. 3).

\section{Independent variable}

In this study, three independent variables were selected, including climatic comfort indicator of the effective temperature (ET), temperature inversion indicator of environmental lapse rate (ELR), and temporal indicator of local calendar events.

The method of effective temperature (ET) was used for calculating the occurrences of thermal comfort conditions during 365 days in 2018. Firstly, Mieczkowski (1985) described the general findings of the human comfort and tourism climatic index, assuming the ET index, which was a measure of temperature taking the effect of relative humidity into account (Amelung et al. 2007). A modified and standardized model of effective temperature has promoted by Spangolo and de Dear (2003) titled 


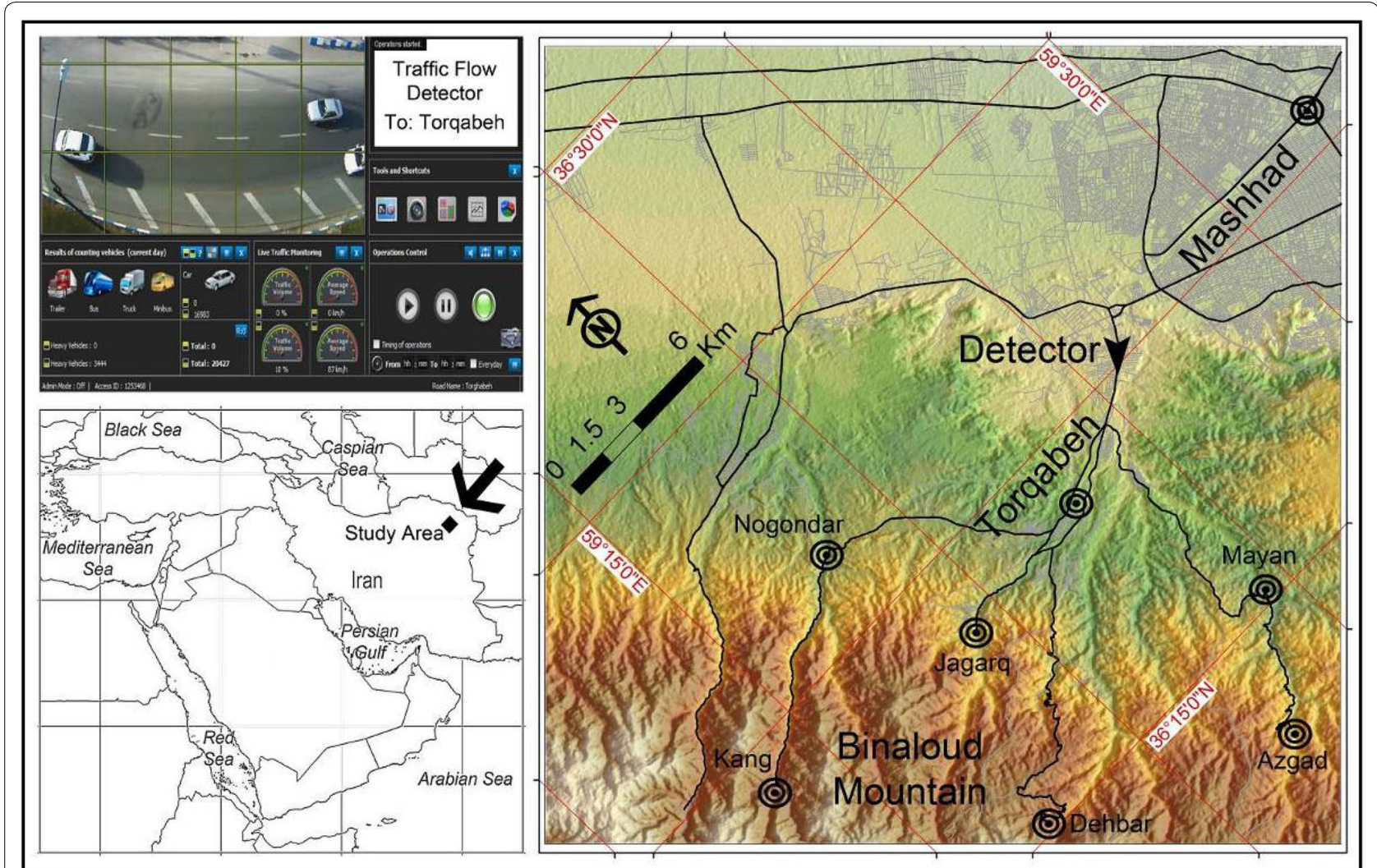

Fig. 1 General position and geographical situation of the study area including the location of traffic flow detector of departing road from Mashhad to Torqabeh city

outdoor standard effective temperature. In this research, the diurnal calculation of ET was considered to compare together with traffic flow day-to-day using the below equation (Eludoyin et al. 2014):

$$
E T=T-0.4(T-10)\left(1-\frac{H}{500}\right)
$$

where $\mathrm{T}$ is the mean temperature of the air $\left({ }^{\circ} \mathrm{C}\right)$, and $\mathrm{H}$ is relative humidity (\%). Each daily ET threshold for a comfortable climate, ranging from 18.9 to $25.6{ }^{\circ} \mathrm{C}$, was coded 1 , which was representing the occurrence of climatic comfort in a day (Eludoyin et al. 2014). Contrarily, the daily values of ET above and below the threshold of comfortable climate were coded 0 , representing noncomfortable conditions. Owing to data accessibility and completeness of time series, the climatic elements of air temperature and relative humidity were extracted from the Asia Pacific Data Research Center data set via http:// apdrc.soest.hawaii.edu/las/getUI.do for the spatial location of the study area $\left(36^{\circ}-37^{\circ} \mathrm{N} \times 59^{\circ}-60^{\circ} \mathrm{E}\right)$.

The inversion indicator defines a positive upward temperature gradient is the lowest part of the troposphere (Fochesatto 2015). In this research, the surface-based temperature inversions located from land surface to $150 \mathrm{~m}$ above ground level (AGL) was estimated named as radiation inversion. Radiation inversions typically occur at the surface when there is radiation loss to balance the surface cooling due to outgoing long-wave radiation (Iacobellis et al. 2009). In this study, an environmental lapse rate (ELR) was used to measure the occurrences of temperature inversion across the surface layer (at $0-150 \mathrm{~m} \mathrm{AGL}$ ) as below equation (Schultz et al. 2000)

$$
\Gamma=\frac{D T}{D Z}
$$

where, $\Gamma$ is the environmental lapse rate (ELR), DT is a temperature gradient across surface layer $\left({ }^{\circ} \mathrm{C}\right)$ at $0-150 \mathrm{~m}$ $\mathrm{AGL}$, and DZ is the thickness of the surface layer $(\mathrm{m})$. The positive values of daily ELR $(\Gamma>0)$ represent the stable atmosphere and occurrences of temperature inversion. Each daily ELR above 1 was coded 1, representing the occurrence of temperature inversion in a day. Contrarily, the daily values of ELR below 1 were coded 0 , 


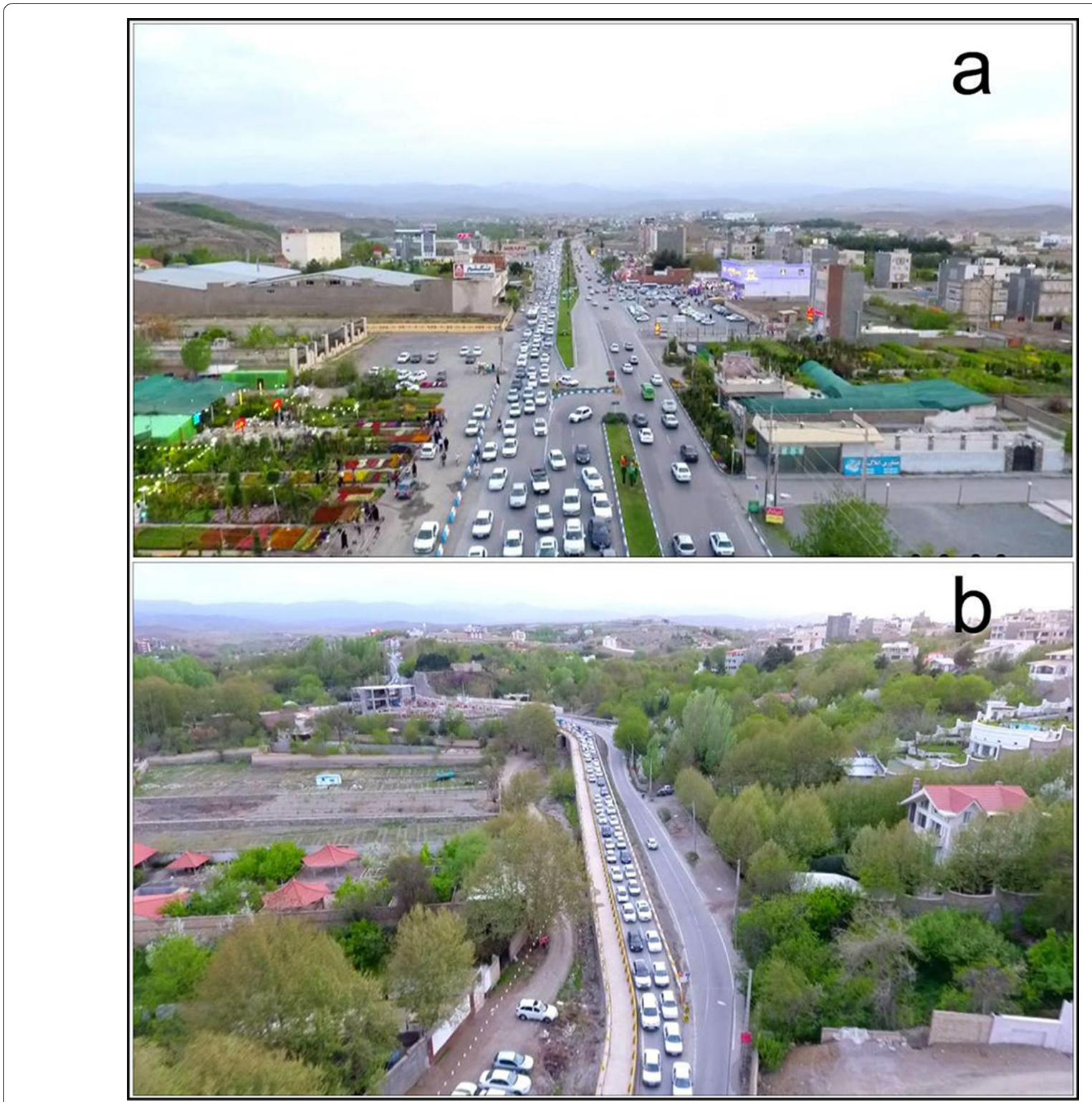

Fig. 2 General perspective of the road from the Mashhad to Torqabeh city $\mathbf{a}$ among the urban settlements and $\mathbf{b}$ among the touristic resorts (March 2019)

representing non-inversion conditions. The temperature gradient data for levels of 0 and 150 m AGL were obtained based on the upper air sounding data and vertical air profiles from the University of Wyoming upper air sounding database via http://weather.uwyo.edu/upper air/sounding.html during 365 days of 2018 for Mashhad Radiosonde station (code: 40745).

Eventually, the local calendar holidays and occasional vacations, as the last independent variable, were achieved from the calendar center of Iran via https://calendar. ut.ac.ir. In this regard, all local calendar events were considered in addition to the cycle of weekend vacation of Fridays to analyze of temporal effects of vacations on traffic flow. Owing to non-official status, the school holidays in summer months were not considered in this study.

\section{Data analysis}

The data time series were arranged into diurnal, weekly, and monthly scales to apply in correlation tests using SPSS software. For this purpose, the range of variables was estimated and then was controlled based on quality 
Table 1 Hourly frequency of total traffic flow in 2018, after the total hour-by-hour detector of total vehicles in the study area

\begin{tabular}{|c|c|}
\hline Hour (UTC) & $\begin{array}{l}\text { Traffic } \\
\text { flow (total } \\
\text { vehicles) }\end{array}$ \\
\hline 1 & 383,915 \\
\hline 2 & 186,106 \\
\hline 3 & 88,321 \\
\hline 4 & 45,747 \\
\hline 5 & 62,447 \\
\hline 6 & 269,090 \\
\hline 7 & 586,717 \\
\hline 8 & 788,110 \\
\hline 9 & 842,385 \\
\hline 10 & 888,927 \\
\hline 11 & 967,766 \\
\hline 12 & 999,399 \\
\hline 13 & $1,074,129$ \\
\hline 14 & $1,190,401$ \\
\hline 15 & $1,149,036$ \\
\hline 16 & $1,167,979$ \\
\hline 17 & $1,194,200$ \\
\hline 18 & $1,347,555$ \\
\hline 19 & $1,457,964$ \\
\hline 20 & $1,358,817$ \\
\hline 21 & $1,164,620$ \\
\hline 22 & 999,156 \\
\hline 23 & 888,032 \\
\hline 24 & 727,800 \\
\hline Total & $19,828,619$ \\
\hline
\end{tabular}

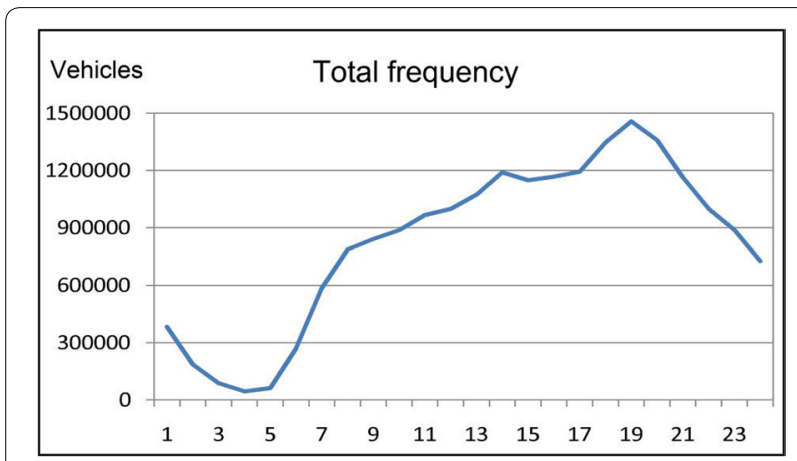

Fig. 3 Distribution of detecting vehicles in each hour based on the total frequency of vehicles in 2018

and constancy validation, confirming the accuracy of data for 354 days, i.e., 0.97 of confidence level. Ultimately, the statistical attitude was considered to estimate the correlation coefficients between three independent variables [including effective temperature (ET), environmental lapse rate (ELR), and calendar vacations] and one dependent variable of traffic flow (total vehicles) by Pearson test. The significant levels dominantly obtained at above $98 \%$ of confidence level (Sig. $<0.02$ ).

Ultimately, a hierarchical clustering analysis (HCA) was used for validating the data correlations. HCA method, same as principal component analysis (PCA), is used to classify cases into subjective classes (clusters) based on similarities within a group and dissimilarities between groups of variables (Mansouri Daneshvar et al. 2013). HCA method is known for its ability to divide the dataset into homogeneous and distinct groups (Shukla et al. 2000). In this study, the HCA method was used to make a proximity matrix of months based on squared Euclidean distance measure and a dendrogram output to classify the cases (months) using Ward's method for the linkage rule.

\section{Results and discussion Traffic flow data}

In the first step, the traffic flow data were transferred from the raw hour-by-hour data to composed day-to-day data for the whole 365 days of 2018. In this period, the loop detector of the traffic control center has detected equal 19,828,619 vehicles, carrying out from Mashhad to the Torqabeh region. Averagely about 54,300 vehicles were recorded for diurnal traffic flow for each weekday in 2018. The highest and lowest traffic flow data were observed for calendar dates of 2018/12/23 and $2018 / 12 / 04$ with a frequency of 81,659 and 42,718 vehicles. The diurnal traffic flow was evaluated based on the monthly cycle in the next step. All traffic flow data, referring to the total vehicles, were distributed in the category of 12 months from January to December (Table 2). The distributive data revealed that the highest and lowest traffic flow data for August and January months with a total frequency of $1,977,567$ and $1,353,878$ vehicles, respectively. The monthly cycle of traffic flow was shown in Fig. 4a. The minima frequency of traffic flow in winter months, especially in January, at least refers to the transportation of local communities in Torqabeh region and its surrounding villages, while the maxima frequency of traffic flow in summer months, especially in August, refers to the transportation of touristic activities, recreation, and leisure. By elimination the flow of 1,353,878 vehicles, as minima frequency of local transportation, from all monthly flow data, the traffic flow of touristic transportation was calculated in the study area with a total frequency of 3,582,083 vehicles. This value indicates the touristic contribution to traffic flow, departing from Mashhad to Torqabeh, as 18\% from total transportation. As well, the mean daily frequency of total vehicles in each 
Table 2 Monthly distribution of traffic flow in 2018, after the total hour-by-hour detector of total vehicles in the study area

\begin{tabular}{llcl}
\hline No. & Time & \multicolumn{2}{l}{ Traffic flow (vehicles) } \\
\cline { 3 - 4 } & & Monthly total & Diurnal mean \\
\hline 1 & Jan & $1,353,878$ & 43,673 \\
2 & Feb & $1,379,283$ & 49,260 \\
3 & Mar & $1,746,474$ & 56,338 \\
4 & Apr & $1,610,058$ & 53,669 \\
5 & May & $1,618,795$ & 52,219 \\
6 & Jun & $1,758,315$ & 58,621 \\
7 & Jul & $1,872,249$ & 60,395 \\
8 & Aug & $1,977,567$ & 63,792 \\
9 & Sep & $1,690,535$ & 56,351 \\
10 & Oct & $1,573,301$ & 50,752 \\
11 & Nov & $1,624,418$ & 54,147 \\
12 & Dec & $1,623,746$ & 52,379 \\
Total & - & $19,828,619$ & 54,300 \\
\hline
\end{tabular}

month was presented in Fig. 4b. On this basis, the highest and lowest diurnal traffic flows were observed for August and January months with a mean frequency of 63,792 and 43,673 vehicles, respectively.

In the last step, the diurnal traffic flow was evaluated based on the weekly cycle. For this purpose, the traffic flow data were distributed in the category of 7 days from Saturday to Friday (official vacation in the local calendar) (Table 3). The distributive data revealed that the highest and lowest traffic flow data for Fridays and Sundays with a total frequency of 3,453,365 and 2,570,885 vehicles, respectively. Based on the field observations, most piece of the traffic flow in Fridays depends on touristic-based transportations. Averagely, about 66,400 vehicles were recorded for the mean daily frequency of traffic flow at each Friday in 2018. Consequently, as the total frequency of vehicles in all Fridays, a total rate of about 3,500,000 vehicles ( $18 \%$ of total transportation) was assumed as a realistic frequency for the touristic contribution to the total transportation in the study area.

\section{Temporal events of local calendar}

Based on the events of occasional holiday and vacations in the local calendar, all diurnal vacations were distributed in the category of 12 months from January to December (Table 4). The result revealed a sum value of 80 days for official holidays (Fridays) and occasional vacations (religious and national ceremonies) in 2018. The most calendar vacations belong to March with 14 days, which depends on the national ceremony of Nowruz (spring equinox). In Table 5, the percentage quota of traffic flow for calendar vacations and ordinary days revealed that about $25 \%$ of total traffic flow corresponds to $22 \%$ of total days in 2018 , referring to vacations. With a calendar viewpoint, $\sim 25 \%$ of total transportation (about $5,000,000$ vehicles) was assumed as the touristic share of the total transportation in the study area. The most piece of touristic transportation occurred on the weekend days (Fridays) during the year, which includes about $65 \%$ of annual vacation days.

\section{Climatic indices}

According to the climatic reanalyzed daily data and Eq. (1), the mean daily calculation of ET was produced. In parallel, the environmental lapse rate (ELR) was calculated based on an upper air sounding data and Eq. (2). In Table 4, the distribution of total days, having the thermal comfort indicator of ET or temperature inversion indicator of ELR, were estimated for each month in 2018. On this basis, the sum frequency of 204 and 208 days was obtained for days with occurrences of ET and ELR, respectively.

On this basis, the highest and lowest frequency of ET days was estimated for August and January months, with a total value of 31 and 0 days, respectively. Besides, the highest and lowest frequency of ELR days was estimated for January and July months, with a total value of 26 and 3 days, respectively. The inversion indicator of ELR, as an adverse weather signal during human activates, has a contradiction with the climatic comfort of the ET index. Hence, their effects in the study area can result in a different role in transportation and tourism.

\section{Discussion}

The main indication of a discussion about the climatic and non-climatic effects on traffic flow relates to the estimation of the rank of correlations by grouping the variables as dependent and independent ones. For this purpose, correlation coefficients between three independent variables (ET, ELR, and vacations) and one dependent variable of traffic flow (total vehicles) were estimated based on two temporal scales of daily ( $\mathrm{N}=365$ days) and monthly ( $\mathrm{N}=12$ months).

In this regard, the correlation test between the aforementioned variables was examined based on a daily temporal scale, and a relatively positive correlation $(\mathrm{R}=+0.453)$ was calculated between traffic flow and local vacations at $99 \%$ of confidence level (Sig. $=0.01$ ), revealing the possible calendar effect on transportation (Table 6). A relatively positive correlation $(\mathrm{R}=+0.348)$ was also calculated between traffic flow and comfortable climatic index of ET at 99\% of confidence level (Sig. =0.01), exposing the possible role of a comfortable climate in the traffic flow. A significant correlation was 


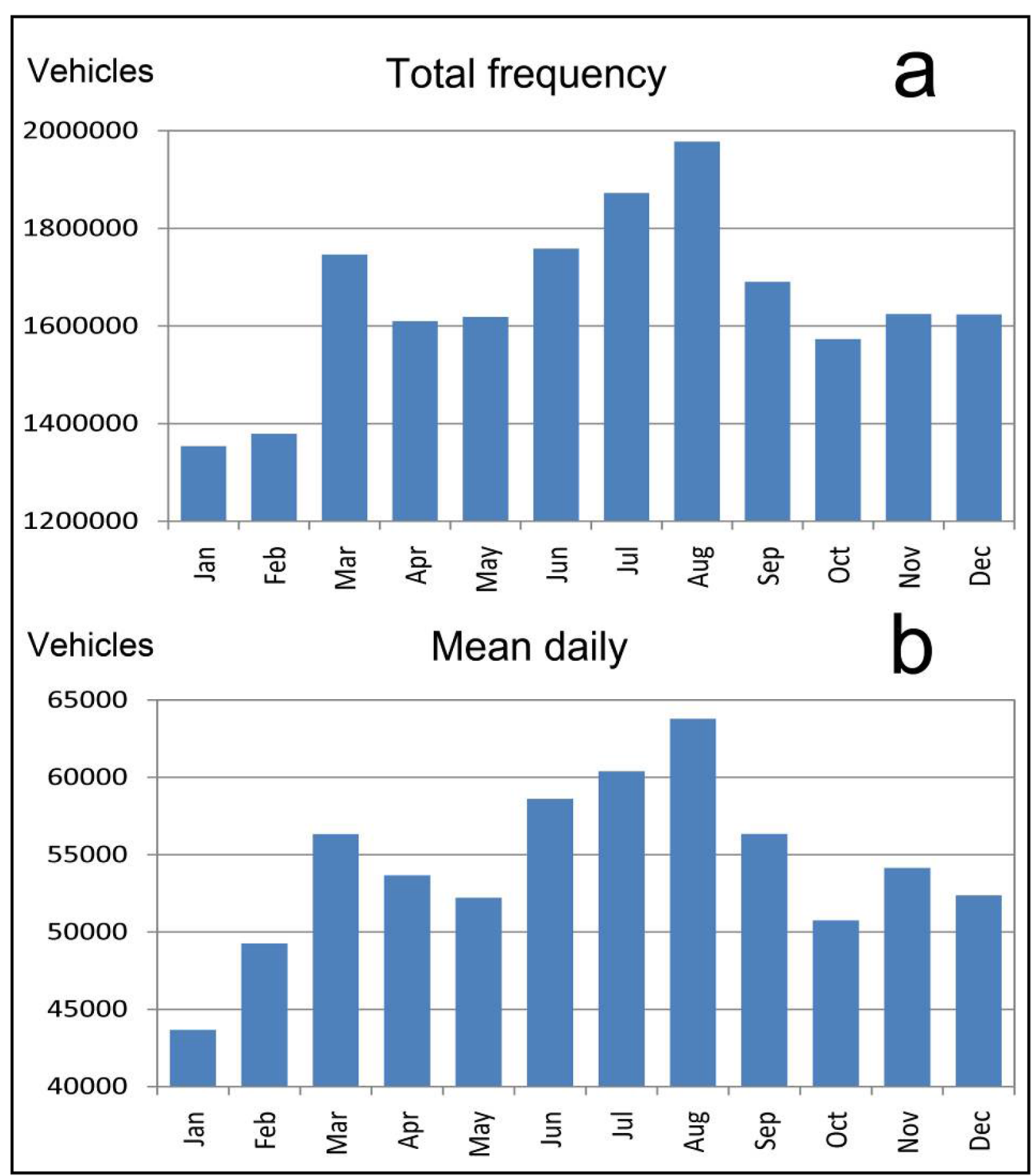

Fig. 4 Distribution of detecting vehicles in each month based on a total frequency and $\mathbf{b}$ mean daily frequency of vehicles in 2018

not observed between traffic flow and the inversion indicator of ELR. As a result, diurnal links exposed the weak effectiveness of the climatic or non-climatic variables on the frequency of total vehicles.

In addition to the diurnal scale, the correlation test was examined based on a monthly temporal scale. Result revealed a relatively significant and positive correlation $(\mathrm{R}=+0.339)$ at $72 \%$ of confidence level $($ Sig. $=0.28)$ between traffic flow and local vacations (Table 7). A strong and noticeable positive correlation $(\mathrm{R}=+0.732)$ at $99 \%$ of confidence level $($ Sig. $=0.01)$ was also calculated between traffic flow and comfortable climatic index of ET, exposing the increasing effective role of a comfortable climate in traffic flow during the monthly cycle. Contrarily, a significant negative correlation $(R=-0.652)$ at $98 \%$ of confidence level (Sig. $=0.02)$ was observed between traffic flow and the inversion indicator of ELR, revealing the decreasing effect of adverse climate on the transportation system. Consequently, monthly links exposed to the more effective and significant role of the local climatic (positive or negative) on the frequency of the total vehicles. This fact revealed that the transportation system in the 
Table 3 Weekly distribution of traffic flow in 2018 , after the total hour-by-hour detector of total vehicles in the study area

\begin{tabular}{llll}
\hline No. & Time & \multicolumn{2}{c}{ Traffic flow (vehicles) } \\
\cline { 3 - 4 } & & Weekly total & Diurnal mean \\
\hline 1 & Sat & $2,819,435$ & 54,220 \\
2 & Sun & $2,570,885$ & 49,190 \\
3 & Mon & $2,667,322$ & 50,327 \\
4 & Tue & $2,665,165$ & 51,253 \\
5 & Wed & $2,706,969$ & 52,057 \\
6 & Thu & $2,945,478$ & 56,644 \\
7 & Fri & $3,453,365$ & 66,411 \\
Total & - & $19,828,619$ & 54,300 \\
\hline
\end{tabular}

Table 4 Monthly distribution of total days with calendar vacations, thermal comfort indicator of ET, and temperature inversion indicator of ELR

\begin{tabular}{llccc}
\hline No. & Time & Vacations (day) & ET (day) & ELR (day) \\
\hline 1 & Jan & 4 & 0 & 26 \\
2 & Feb & 6 & 4 & 18 \\
3 & Mar & 14 & 22 & 22 \\
4 & Apr & 7 & 18 & 17 \\
5 & May & 5 & 30 & 16 \\
6 & Jun & 9 & 30 & 11 \\
7 & Jul & 5 & 27 & 3 \\
8 & Aug & 7 & 31 & 11 \\
9 & Sep & 6 & 29 & 24 \\
10 & Oct & 5 & 12 & 19 \\
11 & Nov & 8 & 1 & 20 \\
12 & Dec & 4 & 0 & 21 \\
Total & - & 80 & 204 & 208 \\
\hline
\end{tabular}

Table 5 The percentage quota of traffic flow for calendar vacations and ordinary days

\begin{tabular}{lccccc}
\hline Calendar event & \multicolumn{2}{l}{ Total vacations } & & \multicolumn{2}{l}{ Traffic flow } \\
\cline { 2 - 3 } & (Days) & $\mathbf{( \% )}$ & & (Vehicle) & (\%) \\
\hline Vacation & 80 & 0.22 & & $5,033,220$ & 0.25 \\
Ordinary & 285 & 0.78 & & $14,795,399$ & 0.75 \\
Sum & 365 & 1.00 & & $19,828,619$ & 1.00 \\
\hline
\end{tabular}

Table 6 Correlation test between variables based on daily summarized data $(\mathbf{N}=365)$

\begin{tabular}{llllc}
\hline Variable & Test & $\begin{array}{l}\text { Calendar } \\
\text { vacations }\end{array}$ & Climatic comfort & Inversion \\
\hline Traffic flow & Correlation (R) & 0.453 & 0.348 & -0.051 \\
& Sig. (2-tailed) & 0.01 & 0.01 & 0.33 \\
\hline
\end{tabular}

Table 7 Correlation test between variables based on monthly summarized data $(\mathrm{N}=12)$

\begin{tabular}{llllc}
\hline Variable & Test & $\begin{array}{l}\text { Calendar } \\
\text { vacations }\end{array}$ & Climatic comfort & Inversion \\
\hline Traffic flow & Correlation (R) & 0.339 & 0.732 & -0.652 \\
& Sig. (2-tailed) & 0.28 & 0.01 & 0.02 \\
\hline
\end{tabular}

study area is associated with the direct effects of the local climate, at least in the monthly cycle.

A hierarchical clustering analysis (HCA) was used to derive the main clusters of cases (monthly cycles) based on the data variables. In this regard, the values of variables were transformed to standard values (z-score) and were used to produce a proximity matrix (Table 8 ), revealing that the months could be clustered into some classes as illustrated graphically in a dendrogram (Fig. 5) with rescaled distance cluster combination of 10 . According to this figure, the cases of 12 months were classified into three cycles of monthly clusters. The case of Jun, July, and August months was categorized as summer peak flow, the case of March month was categorized as spring equinox traffic flow, and the case of other months was categorized as annual base flow.

The local climate has direct effects, influencing the traffic flows in urban areas (Jaroszweski et al. 2014). Furthermore, local climate directly influences the tourism seasons, destination costs, and the quality of environmental resources, which in turn influences the flow of tourists (Scott et al. 2008). In accordant the evidence investigated by Hall et al. (2004), Koetse and Rietveld (2009) and Gasper et al. (2011), the results revealed that societal-based variations such as touristic transportation might be affected by climatic comfort conditions because transpiration system of the study area is strongly affected by the alteration of climatic comfort index. In vice versa, the adverse climatic condition has a negative effect on the traffic flow. For instance, adverse climate such as heavy precipitation and heat waves can significantly reduce the flow and speed of vehicles (Agarwal et al. 2006; Datla and Sharma 2008). Similarly, a decreasing effect of adverse climate (temperature inversion index) was identified in the transportation system. According to the literature, traffic flow and roads are usually sensitive to adverse variables of climatic conditions (Reed et al. 2010; Rowan et al. 2013).

Ultimately, the results revealed a relative relationship between traffic flow and local calendar events on the diurnal scale, not in the monthly cycle. This fact describes that the traffic flow and touristic transportation in the study area are less affected by local calendar holidays and occasional vacations. Hence, the decision-makers in the study area sternly need a fundamental climatic calendar 
Table 8 Proximity matrix between 12 months (cases) based on squared Euclidean distance in HCA

\begin{tabular}{|c|c|c|c|c|c|c|c|c|c|c|c|c|}
\hline Case & Jan & Feb & Mar & Apr & May & Jun & Jul & Aug & Sep & Oct & Nov & Dec \\
\hline Jan & 0.0 & 2.2 & 21.1 & 7.1 & 10.2 & 19.3 & 25.8 & 24.6 & 9.2 & 3.7 & 5.3 & 2.9 \\
\hline Feb & 2.2 & 0.0 & 14.9 & 3.0 & 6.1 & 10.9 & 16.4 & 16.9 & 7.7 & 1.7 & 2.6 & 2.7 \\
\hline Mar & 21.1 & 14.9 & 0.0 & 7.7 & 12.3 & 6.6 & 19.9 & 11.5 & 8.8 & 12.3 & 7.9 & 16.4 \\
\hline Apr & 7.1 & 3.0 & 7.7 & 0.0 & 1.4 & 2.9 & 7.9 & 6.1 & 2.3 & 0.9 & 2.1 & 3.5 \\
\hline May & 10.2 & 6.1 & 12.3 & 1.4 & 0.0 & 3.3 & 6.2 & 5.2 & 1.9 & 2.2 & 6.6 & 6.1 \\
\hline Jun & 19.3 & 10.9 & 6.6 & 2.9 & 3.3 & 0.0 & 4.1 & 2.0 & 5.4 & 6.7 & 7.7 & 11.7 \\
\hline Jul & 25.8 & 16.4 & 19.9 & 7.9 & 6.2 & 4.1 & 0.0 & 2.5 & 11.9 & 10.4 & 14.2 & 14.3 \\
\hline Aug & 24.6 & 16.9 & 11.5 & 6.1 & 5.2 & 2.0 & 2.5 & 0.0 & 6.8 & 9.4 & 11.4 & 13.3 \\
\hline Sep & 9.2 & 7.7 & 8.8 & 2.3 & 1.9 & 5.4 & 11.9 & 6.8 & 0.0 & 2.9 & 5.8 & 5.9 \\
\hline Oct & 3.7 & 1.7 & 12.3 & 0.9 & 2.2 & 6.7 & 10.4 & 9.4 & 2.9 & 0.0 & 2.0 & 1.2 \\
\hline Nov & 5.3 & 2.6 & 7.9 & 2.1 & 6.6 & 7.7 & 14.2 & 11.4 & 5.8 & 2.0 & 0.0 & 2.1 \\
\hline Dec & 2.9 & 2.7 & 16.4 & 3.5 & 6.1 & 11.7 & 14.3 & 13.3 & 5.9 & 1.2 & 2.1 & 0.0 \\
\hline
\end{tabular}

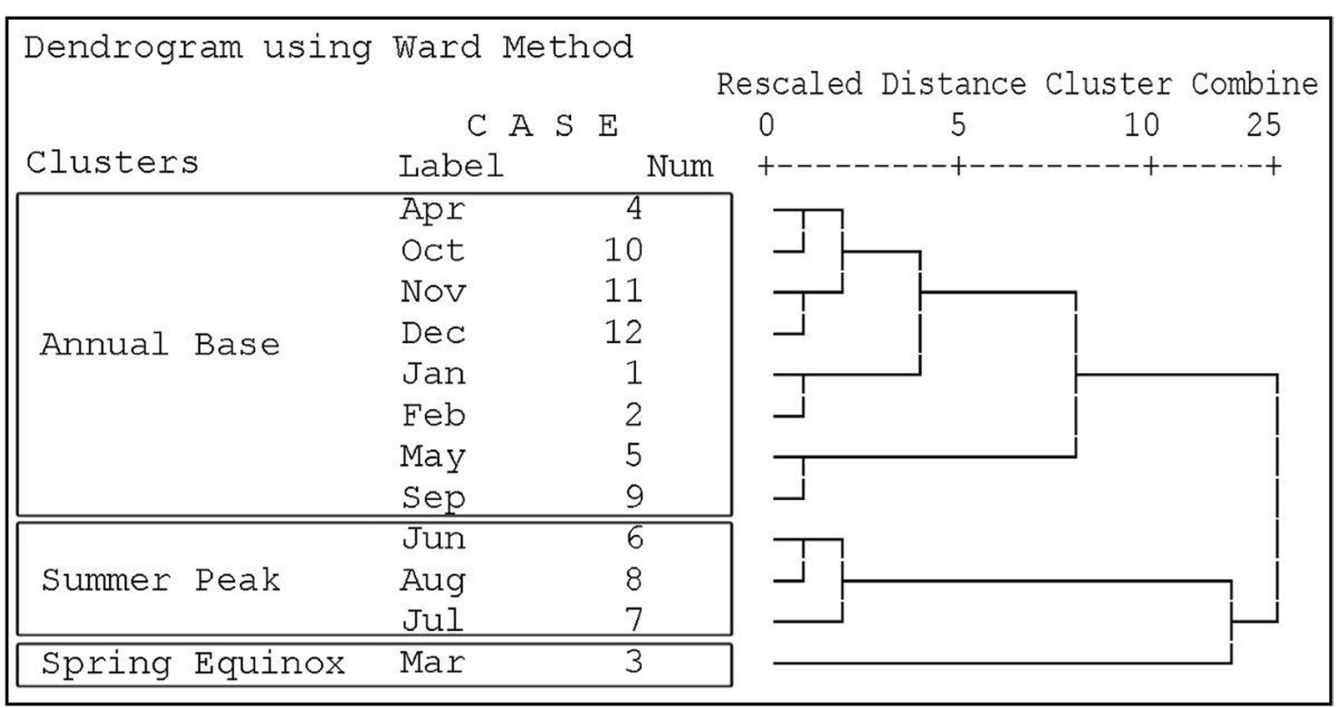

Fig. 5 Clustering dendrogram of the months based on traffic flow, extracted from HCA method in SPSS software

for management, tourism transportation, and traffic flow instead of the current local calendar.

\section{Conclusion}

This study aimed to evaluate variables that influence traffic flow in a touristic road in western Mashhad city to Torqabeh region, Iran, as a proper way to detect the touristic share of all transportation. The mentioned road averagely transmits total vehicles equal to $\sim 20$ million cars per year only in a departing line. For the study purpose, the traffic flow data were extracted from the hourby-hour data using the loop detector of the traffic control center for whole 365 days in 2018, which was obtained as an entirety equal to $19,828,619$ vehicles. Furthermore, three independent variables were selected, including climatic comfort indicator of the effective temperature (ET), temperature inversion indicator of environmental lapse rate (ELR), and temporal indicator of local calendar events. All aforementioned variables, by diurnal, weekly, and monthly scales, were summarized averagely to analyze, acquiring correlation analysis.

The highest and lowest diurnal traffic flows were observed for August and January months with a mean frequency of 63,792 and 43,673 vehicles, respectively. Averagely, about 66,400 and 54,300 vehicles were recorded for the mean daily frequency of traffic flow at each weekday and Friday in 2018, respectively. Based on the temporal cycles of weekends and vacations, a 
rate of $18-25 \%$ of total transportation was assumed as a realistic frequency for the touristic share of the total transportation in the study area.

Statistical correlation tests in diurnal and monthly scales exposed to the more effective and significant role of the local climatic on the frequency of total vehicles without a strong association between calendar events and traffic flow. In this regard, a strong and noticeable positive correlation $(\mathrm{R}=+0.732)$ was calculated between traffic flow and comfortable climatic index of ET, exposing the increasing effective role of a comfortable climate in traffic flow during the monthly cycle. Meanwhile, a significant negative correlation $(R=-0.652)$ was observed between traffic flow and the inversion indicator of ELR, revealing the decreasing effect of adverse climate on the transportation system.

This fact revealed that the transportation system in the study area is associated with the direct effects of the local climate in the monthly cycle, which was confirmed using hierarchical clustering analysis (HCA) through a dendrogram, including three cycles of monthly clusters. Ultimately, the result described that the traffic flow and touristic transportation in the study area are less affected by local calendar holidays and occasional vacations. Hence, the decision-makers in the study area sternly need a fundamental climatic calendar for management the tourism transportation and traffic flow instead of the current local calendar.

\section{Abbreviations}

AGL: above ground level; ASL: above sea level; ET: effective temperature; ELR: environmental lapse rate; HCA: hierarchical clustering analysis.

\section{Acknowledgements}

We thank anonymous reviewers for technical suggestions on data interpretations.

\section{Authors' contributions}

All authors were equally involved in analyzing and editing the paper. All authors read and approved the final manuscript.

\section{Funding}

This study was not funded by any grant.

\section{Availability of data and materials}

The data that support the findings of this study are available from the corresponding author upon request.

\section{Ethics approval and consent to participate}

This article does not contain any studies with participants performed by any of the authors.

\section{Informed consent}

Informed consent was obtained from individual participant included in the study.

\section{Consent for publication}

Not applicable.

\section{Competing interests}

The authors declare that they have no competing interests.

\section{Author details}

${ }^{1}$ Department of Urban Planning and Design, Islamic Azad University, Mashhad Branch, Mashhad, Iran. ${ }^{2}$ Department of Art and Architecture, Islamic Azad University, Mashhad Branch, Mashhad, Iran. ${ }^{3}$ Department of Geography and Natural Hazards, Research Institute of Shakhes Pajouh, Isfahan, Iran.

Received: 8 November 2019 Accepted: 5 December 2019

Published online: 12 December 2019

\section{References}

Abdel-Aal MM, El-Maaty AE, Abo Samra HA (2018) Factors affecting road capacity under non-ideal conditions in Egypt. Nova J Eng Appl Sci $7(1): 1-13$

ABS (2001) ABS views on remoteness, Australia (CAT.NO:1244). Australian Bureau of Statistics, Canberra

Agarwal M, Maze TH, Souleyrette R (2006) The weather and its impact on urban freeway traffic operations. In: Proceedings of 85th annual meeting of the transportation research board, Washington, DC, Transportation Research Board of the National Academies, 06-1439

Amelung B, Blazejczyk K, Matzarakis A (2007) Climate change and tourism: assessment and coping strategies. Institute of Geography and Spatial Organization, Freiburg

Arasan VT, Koshy R (2005) Methodology for modeling highly heterogeneous traffic flow. J Transp Eng 131(7):544-555

Bertolini L, le Clercq F, Kapoen L (2005) Sustainable accessibility. Transp Policy 12:207-220

Bikdeli S (2019) Redevelopment modeling for land suitability evaluation of the suburb brown-fields using fuzzy logic and GIS, northeastern Iran. In: Environment, development and sustainability, pp 1-20

Bikdeli S, Shafaqi S, Vosouqi F (2017) Accessibility modeling for land use, population and public transportation in Mashhad, NE Iran. Spatial Inf Res 25(3):481-489

Cools M, Moons E, Wets G (2010) Assessing the impact of weather on traffic intensity. Weather Clim Soc 2:60-68

Datla S, Sharma S (2008) Impact of cold and snow on temporal and spatial variations of highway traffic volumes. J Transp Geogr 16:358-372

Eludoyin OM, Adelekan IO, Webster R, Eludoyin AO (2014) Air temperature relative humidity, climate regionalization and thermal comfort of Nigeria. Int J Climatol 34(6):2000-2018

Fochesatto GJ (2015) Methodology for determining multilayered temperature inversions. Atmos Meas Tech 8:2051-2060

Gasper R, Blohm R, Ruth M (2011) Social and economic impacts of climate change on the urban environment. Curr Opin Environ Sustain 3:150-157

Hall CM, Timothy DJ, Duval DT (2004) Security and tourism—towards a new understanding? J Travel Tourism Mark 15:1-18

Hijmans RJ, Cameron SE, Parra JL, Jones PG, Jarvis A (2005) Very high resolution interpolated climate surfaces for global land areas. Int J Climatol 25(15):1965-1978

lacobellis SF, Norris JR, Kanamitsu M, Tyree M, Cayan DC (2009) Climate variability and California low-level temperature inversions. California Climate Change Center. 48 pp

Jaroszweski D, Hooper E, Chapman L (2014) The impact of climate change on urban transport resilience in a changing world. Prog Phys Geogr 38(4):448-463

Jenelius E, Koutsopoulos HN (2013) Travel time estimation for urban road networks using low frequency probe vehicle data. Transp Res Part B Methodol 53:64-81

Kim K (2018) Investigation on the effects of weather and calendar events on bike-sharing according to the trip patterns of bike rentals of stations. $J$ Transp Geogr 66:309-320

Kitamura R (2009) A dynamic model system of household car ownership, trip generation, and modal split: model development and simulation experiment. Transportation 36:711-732

Koetse MJ, Rietveld P (2009) The impact of climate change and weather on transport: an overview of empirical findings. Transp Res Part D Transp Environ 14(3):205-221 
Liu S, Zhu X (2004) An integrated GIS approach to accessibility analysis. Trans GIS 8:45-62

Madhuwanthi RAM, Marasinghe A, Rajapakse RPC, Dharmawansa AD, Nomura $S$ (2016) Factors influencing to travel behavior on transport mode choice. Int J Affect Eng 15(2):63-72

Mansouri Daneshvar MR, Bagherzadeh A, Alijani B (2013) Application of multivariate approach in agrometeorological suitability zonation at northeast semiarid plains of Iran. Theor Appl Climatol 114(1-2):139-152

Mieczkowski Z (1985) The tourism climatic index: a method of evaluating world climates for tourism. Can Geogr 29(3):220-233

Rabbani G, Shafaqi S, Rahnama MR (2017) Urban sprawl modeling using statistical approach in Mashhad, northeastern Iran. Model Earth Syst Environ 4(1):141-149

Reed DA, Powell MD, Westerman JM (2010) Energy infrastructure damage analysis for Hurricane Rita. Nat Hazards Rev 11(3):102-109

Rowan E, Evans C, Riley-Gilbert M, Hyman R, Kafalenos R, Beucler B, Rodehorst B, Choate A, Schultz P (2013) Assessing the sensitivity of transportation assets to extreme weather events and climate change. Transp Res Rec 2326:16-23

Schultz DM, Schumacher PN, Doswell CA (2000) The intricacies of instabilities. Mon Weather Rev 128:4143-4148
Scott D, Amelung B, Becken S, Ceron JP, Dubois G, Gössling S, Peeters P, Simpson M (2008) Climate change and tourism: responding to global challenges. United Nations World Tourism Organization, Madrid

Shukla S, Mostaghimi S, Al-Smadi M (2000) Multivariate technique for base flow separation using water quality data. J Hydrol Eng 5(2):172-179

Spagnolo JC, de Dear RJ (2003) A human thermal climatology of subtropical Sydney. Int J Climatol 23:1383-1395

White P (2009) Public transport: its planning, management and operation, 5th edn. Routledge, London

Wixey S, Jones P, Lucas K, Aldridge M (2005) Measuring accessibility as experienced by different socially disadvantaged groups. Transit Studies Group, University of Westminster, London

Yigitcanlar T, Sipe NG, Evans R, Pitot M (2007) A GIS-based land use and public transport accessibility indexing model. Aust Plan 44(3):30-37

\section{Publisher's Note}

Springer Nature remains neutral with regard to jurisdictional claims in published maps and institutional affiliations.

\section{Submit your manuscript to a SpringerOpen ${ }^{\circ}$ journal and benefit from:}

- Convenient online submission

- Rigorous peer review

- Open access: articles freely available online

- High visibility within the field

- Retaining the copyright to your article

Submit your next manuscript at $\boldsymbol{\nabla}$ springeropen.com 